\title{
The importance of genetic study in steroid-resistant nephrotic syndrome
}

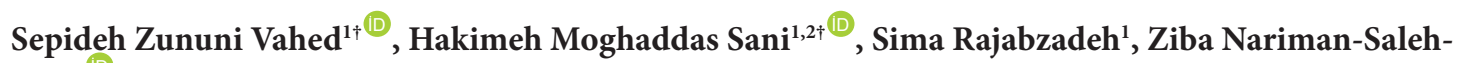 \\ Fam $^{3}{ }^{\mathbb{D}}$, Mina Hejazian', Fatemeh Zununi Vahed ${ }^{1}$, Seyed Mahdi Hosseiniyan Khatibi', Mohammadali \\ Mohajel Shoja $^{4}$, Mohammadreza Ardalan ${ }^{1 *} \mathbb{D}$
}

${ }^{1}$ Kidney Research Center, Tabriz University of Medical Sciences, Tabriz, Iran

${ }^{2}$ School of Life and Environmental Sciences, University of Sydney, New South Wales 2006, Australia

${ }^{3}$ Women's Reproductive Health Research Center, Tabriz University of Medical Sciences, Tabriz, Iran

${ }^{5}$ Department of Surgery, University of Texas Medical Branch, Galveston, TX, USA

\section{A R T I C L E I N F O}

Article Type:

Review

\section{Article History:}

Received: 22 April 2019

Accepted: 9 August 2019

Published online: 13 September 2019

\section{Keywords:}

Podocytopathy

Proteinuria

Gene mutation

Podocyte

\begin{abstract}
A B S T R A C T
Steroid-resistant nephrotic syndrome (SRNS) is a challenging clinical task. It has heterogeneous etiology and extremely variable clinical outcomes and generally progresses to end-stage renal disease (ESRD). Different gene mutations in podocyte's slit diaphragm, mitochondria, and cytoskeleton proteins, as well as glomerular basement membrane (GBM) have been associated with SRNS. These proteins regulate the function of the glomerular filtration barrier. Advances in genetic approaches and podocytology have led to discover the SRNS-causing genes that lead to a better understanding of the drug resistance. More than 45 genetic mutations have been recognized in the hereditary form of SRNS. This review offers an update on the current knowledge of steroid resistance-causing gene mutations in podocytes. Understanding the specific genes involved in SRNS would guarantee an optimum therapeutic benefit of steroid treatment.
\end{abstract}

Implication for health policy/practice/research/medical education:

The clinic needs novel therapeutic for patients with inherited glomerular disease that up to now have been suffering from lack of any specific and effective treatment. This review offers an update on the current knowledge of steroid resistance-causing gene mutations in podocytes.

Please cite this paper as: Zununi Vahed S, Moghaddas Sani H, Rajabzadeh S, Nariman-Saleh-Fam Z, Hejazian M, Hosseiniyan Khatibi SM, Mohajel Shoja M, et al. The importance of genetic study in steroid-resistant nephrotic syndrome. J Renal Inj Prev. 2019;8(4):271-282. DOI: 10.15171/jrip.2019.51.

\section{Introduction}

Steroid-resistant nephrotic syndrome (SRNS) is a challenging clinical task since it has heterogeneous etiology and extremely variable clinical outcomes (1). The prevalence of SRNS is $15 \%$ in children and $40 \%$ in adults (2). Renal histology in most of SRNS cases displays the presence of focal segmental glomerulosclerosis (FSGS), proliferative glomerulonephritis, and minimal change disease $(\mathrm{MCD})$ (2,3). In children and adults, administration of high dose steroids, calcineurin inhibitors (CNI), cyclophosphamide $(\mathrm{CP})$, rituximab, and mycophenolate mofetil have been exerted variable success rates (4). Even though in some cases persistent or temporary remission can be obtained by immunosuppressive agents, some others display a multidrug-resistant phenotype (5). Most of the SRNS patients generally progress to end-stage renal disease (ESRD) and post-transplant recurrence $(6,7)$.

The exact molecular pathophysiology of SRNS needs to be understood, however, genetic abnormalities or immune system dysfunction have been reported (8). A third of SRNS patients have one mutation in their podocyte genes, while the disease in others is triggered by an unclear circulating factor (3). Recently, abnormalities in podocyte genes have been recognized in congenital NS and SRNS cases $(5,9)$.

Over the past 20 years, progresses in genomic tools such 
as next-generation sequencing (NGS) and chromosomal microarray (CMA) have discovered that more than 50 genes are connected with SRNS $(3,10)$. Most of these genes encode proteins that are located in the podocyte, slit diaphragm (SD), and glomerular filtration barrier (GFB), therefore, SRNS is considered as a podocytopathy $(3,11)$. Alterations in the architecture of podocyte lead to podocyte dysfunction or loss that increase its permeability and result in proteinuria. When any of the podocyterelated mutations exists, the effects of GCs on the podocytes are blunted and steroid-resistance happens. In this review, an update on recent findings of SRNS-related gene mutations will be put forward.

\section{Glomerular filtration barrier}

Malfunction of the GFB is the common feature found in NS patients. GFB consists of three layers, podocytes, glomerular basement membrane (GBM), and fenestrated endothelium (Figure 1). Podocytes are highly differentiated epithelial cells that are connected by intercellular junctions called SD and create a compact layer on the urinary side of the GFB. GFB acts as a primary ultra-filter (12). The overall negative charge of GFB is related to negatively charged glycocalyx on the surface of podocytes and endothelial cells and also to sialoproteins and heparan sulfate located in GBM (13). Damages to any of the three layers and loss of GFB properties in sieving macromolecules lead to proteinuria. More importantly, podocytes destruction damages GFB integrity. SD interacts with the actin cytoskeleton and triggers signaling pathways involved in podocyte activity such as cell polarity, mechanosensation, endocytosis, and calcium flux (13). Therefore, it is expected that mutations in coding genes of SD components such as WT1, PAX2, and nephrin affect cellular functions and create morphological alterations such as apoptosis, and detachment from the GBM. Moreover, clinical evidence indicates that circulating agents, cytokine imbalance, and immune complex deposition are involved in podocytes injury in NS, since susceptibility to immune factors can be influenced by genomic variants found in these agents (13).

Podocyte single genes and pathogenic pathways of SRNS

Investigations on the disease mechanism have indicated the participation of more than 50 single genes in the induction of SRNS. Corresponding proteins of these genes are mostly located in glomerular podocytes and SD and their mutation is associated with the pathogenesis of SRNS $(6,8)$. Sadowski et al measured the frequency of NPHS2 and WT1 mutations in unrelated families with SRNS and detected $29.5 \%$ single gene cause in families with SRNS (14). Previous data show that most of SRNS patients (85\%) with early-onset of three months and 66\% of patients with the onset of one year of age carry mutations in one of podocyte NPHS1, WT1, LAMB2, or NPHS2 genes (15). However, the frequency of genes mutations varies in different studies and populations. For instance, ADCK $4(0.17 \%)$ is the least common mutation in a study performed on international unrelated families; however, the same gene is the most common mutation (6.67\%) in Chinese children with SRNS (16). Mitochondrial-related gene mutations are also involved in steroid resistance. Beyond diagnostic value, the identification of causative mutations may present therapeutic significances in some patients (2). Table 1 lists an updated number of podocyteSRNS-related genes and their abrogated mechanism after mutation. In the following section, we provide the most reported gene abnormalities associated with SRNS (Figure 1).

\section{Nephrin}

Nephrin protein encodes by NPHS1 gene (38). Different NPHS1 mutations are associated with congenital NS that influence infants before three months of age $(14,39)$. Congenital NS is associated with in-utero proteinuria, post-natal SRNS, and ESRD. Two recognized common mutation defects in NPHS1 are 'Fin major' (c.121delCT) and 'Fin minor' (p.R1109X) in congenital NS patients. Both mutations create premature stop codons at $\mathrm{N}$ - and C-terminal regions of nephrin, respectively, and produce a truncated protein, with impaired SDs function (40).

Due to the absence of native nephrin protein in mutant kidney cells, slits in the SDs are narrowed. Another mutation associated with congenital NS is homozygous p. R1160X mutation that leads to mild complications and spontaneous disease remission in children (41). In addition to congenital NS, compound heterozygosity in NPHS1 gene is detected in early childhood onset NS with late childhood remission in some cases (42). Homozygous or compound heterozygous polymorphisms in NPHS1 are detected in cases suffering from FSGS and SRNS (43), most of these cases were children (in the range of 8 months to seven years). NPHS1 mutations are also reported in a 27-year FSGS case which partially responded to immunosuppression. Hence, NPHS1 mutations are identified in patients with congenital NS and early-onset NS. Moreover, rare mild mutations have been reported in patients with late-onset SRNS.

\section{Podocin}

NPHS2 mutations first found in early-onset autosomal recessive familial and sporadic SRNS (44). NPHS2 gene harbors 8 exons and encodes podocin, an interrelated protein with nephrin. Some mutations in the coding sequence of gene may alter its structure and stability and thus, disrupt its functional association and cause proteinuria (45). NPHS2 mutations are associated with infantile-onset, SRNS accompanied by FSGS, and progression to renal failure. Mutations (about 126) have been reported that mostly correspond for missense 
Table 1. Identified mutations and their role in SRNS-related podocyte genes

\begin{tabular}{|c|c|c|c|c|}
\hline Gene & Chromosome & Mutation & Mechanism of mutation & Ref. \\
\hline$\angle A M B 2$ & $3 p 21.3$ & $\begin{array}{l}\text { c.737G>A/ R246Q } \\
\text { c.253delG /p.Glu85Lysfs*27 } 3 \text { (hom, p, m) }\end{array}$ & $\begin{array}{l}\text { Perturbs polymerization of laminin heterotrimer and secretion of the mutant laminin trimer into the GBM, leading to altered GBM laminin } \\
\text { composition. }\end{array}$ & (17) \\
\hline NUP160 & $11 \mathrm{p}$ & R11733 and E803K & $\begin{array}{l}\text { Both mutations are pathogenic in the patient with SRNS and FSGS. The missense E803K severely impairs nucleocytoplasmic transport and } \\
\text { other NPC-associated functions required for normal nephrocyte physiology. }\end{array}$ & $(18)$ \\
\hline NUP93 & & c. $2137-18 G>A$ & The intronic variant caused exon skipping. & (19) \\
\hline SMARCAL1 & $2 q 35$ & c. $2542 \mathrm{G}>\mathrm{T} / \mathrm{p} . \mathrm{E} 848 \mathrm{x}$ & SWI/SF2-related protein involves in chromatin remodeling, SMARCAL1 possibly regulates expression of podocyte proteins. & $(20)$ \\
\hline TP53RK & $20 q 13$ & c.194A > T, p.Lys65Met & $\begin{array}{l}\text { It is a subunit of KEOPS. Mutation leads to impaired cell proliferation, translational attenuation, ER stress, activation of DDR signaling, } \\
\text { increased apoptosis, and defects in actin regulation, }\end{array}$ & (21) \\
\hline $\mathrm{CFH}$ & $1 q 31$ & c.2195C>T, p.Thr732Met & Dysregulation of alternative pathway of complement at the microvascular level, and capillary wall injury & $(22)$ \\
\hline COQ2 & $4 q 21$ & c. $890 \mathrm{~A}>\mathrm{G} / \mathrm{p} . \mathrm{Y} 297 \mathrm{C}$ & Deficiency in CoQ10 biosynthesis & (23) \\
\hline CoQ6 & $14 q 24$ & c. 1058 C>A /p.A353D & Deficiency in CoQ10 biosynthesis & (24) \\
\hline PDSS2 & $6 q 21$ & $\begin{array}{l}\text { c. } 964 \mathrm{C} \rightarrow \mathrm{T}, \mathrm{p} .322 \text { glutamine to a stop codon/ } \\
\text { c. } 1145 \mathrm{C} \rightarrow \mathrm{T} \text {, p. } 382 \text { Serine to Leucine }\end{array}$ & Deficiency in CoQ10 biosynthesis & (25) \\
\hline ACDK4 & 19 q13 & c.532C>T;p.R178W & Decreases CoQ10 levels and mitochondrial respiratory enzyme activity and reduces migration. & (26) \\
\hline PTPRO & $12 \mathrm{p} 12$ & $\begin{array}{l}\text { c.2627+1G>T (p.Glu854_Trp876del) } \\
\text { c.2745p1G>A (p.Asn888Lysfs*3) }\end{array}$ & $\begin{array}{l}\text { Mutant protein lacks the tyrosine protein phosphatase domain and the substrate-binding regions and prohibits tyrosine phosphorylation of } \\
\text { tight junction proteins which plays a major role in controlling paracellular permeability, cell signaling, and actin cytoskeleton remodeling. }\end{array}$ & (27) \\
\hline GAPVD1 & $9 q 33$ & $\begin{array}{l}\text { c.1240 C.G /p.Leu414Val } \\
\text { c.2810 G .A /p.Arg937Gln }\end{array}$ & Affects binding affinity to nephrin and RAB5, regulator of endocytosis, and podocyte migration rate. & (28) \\
\hline ANKFY1 & $17 p 13$ & c.284 G .T/ p.Arg95Leu & Affects binding affinity to $\mathrm{RAB} 5$ and podocyte migration rate & (28) \\
\hline KANK1 & $9 p 24$ & C1360G >A/ p.E454K & Podocyte dysfunction, probably by dysregulating RHO GTPase signaling & (29) \\
\hline ARHGDIA & $17 q 25$ & $\begin{array}{l}\text { c.358C }>T \text { R } 120 X \\
\text { and c.518 G>T/G173V) }\end{array}$ & Mutations abrogate interaction with RHO GTPases such as RAC1 and CDC42 and result in a migratory phenotypic change in podocytes & (30) \\
\hline ARHGAP24 & $4 q 21$ & c.473A>G /Q158R & Dysregulates Rac1-GAP activity which controls podocyte migration & (31) \\
\hline \multirow[b]{2}{*}{ MAG/2 } & \multirow[b]{2}{*}{$7 q 21$} & Familial: c.3998delG:p.(Gly1333Alafs*141) & \multirow[b]{2}{*}{$\begin{array}{l}\text { Alter actin cytoskeletal regulation through RhoA signaling and possibly } \\
\text { Destroy the SD formation and podocyte foot process effacement, and severe glomerular pathology }\end{array}$} & \multirow[b]{2}{*}{$(32)$} \\
\hline & & $\begin{array}{l}\text { Sporadic: c.64_71delAGGAACCC:p.(Arg22Glyfs*7) } \\
\text { together with c.3526_3533dupCTGGCAGA:p. } \\
\text { (Glu1178Aspfs*9) }\end{array}$ & & \\
\hline
\end{tabular}


Table 1. Continued

\begin{tabular}{|c|c|c|c|c|}
\hline Gene & Chromosome & Mutation & Mechanism of mutation & Ref. \\
\hline CRB2 & $9 q 33$ & $\begin{array}{l}\text { c.1859G >C (p.Cys620Ser) } \\
\text { c.1886G >C p.Cys629Ser }\end{array}$ & It is identified in extracellular tenth EGF-like domain of CRB2 and probably has an important role in CRB2 function in podocytes. & (33) \\
\hline MYO1E & $15 q 22$ & p.A159P/c. $475 \mathrm{G}>\mathrm{C}$ & It is a podocyte cytoskeletal protein; mutation impairs ligand binding and actin interaction in the MYO1E motor domain. & (34) \\
\hline NEIL1 & $15 q 24$ & $\mathrm{E} 181 \mathrm{~K} /$ c. $541 \mathrm{G}>\mathrm{A}$ & Impairs encoding base excision DNA repair glycosylase & (34) \\
\hline NUP93 & $16 q 13$ & $\begin{array}{l}\text { Deletion of exon 13, p.Arg388Trp and } \\
\text { p.Lys442Asn fs*14) } \\
\text { p.Lys442Asnfs*14, p.Gly591Val and p.Tyr629Cys }\end{array}$ & $\begin{array}{l}\text { Impairs pore formation } \\
\text { Disrupt NUP93-SMAD4 or NUP93- importin7 interactions }\end{array}$ & (35) \\
\hline NUP205 & $7 q 33$ & $\begin{array}{l}\text { Homozygous mutation (c.5984T>C) } \\
\text { (p.Phe1995Ser). }\end{array}$ & Abrogates interaction with NUP93 and impairs NPC assembly & (35) \\
\hline XPO5 & $6 \mathrm{p} 21.1$ & $(c .1654 G>A)($ p.Val552lle) & Abrogates SMAD4 interaction and nuclear export & (35) \\
\hline HP & & p.K320N and p.R227P & & (36) \\
\hline NUP107 & $12 q 15$ & (c.2492A>C [p.Asp831Ala]) & Impairs NUP107 and NUP133 interaction and NUP incorporation to NPC & (37) \\
\hline
\end{tabular}

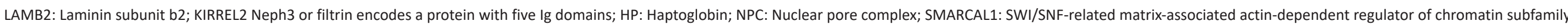

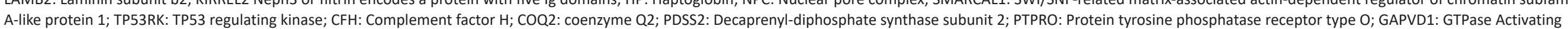

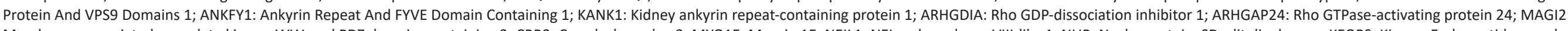

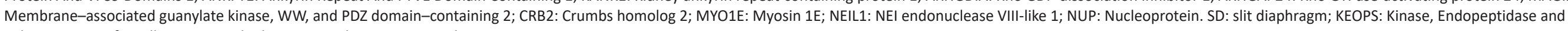
Other Proteins of small Size, ER: endoplasmic reticulum, DDR: DNA damage response. 


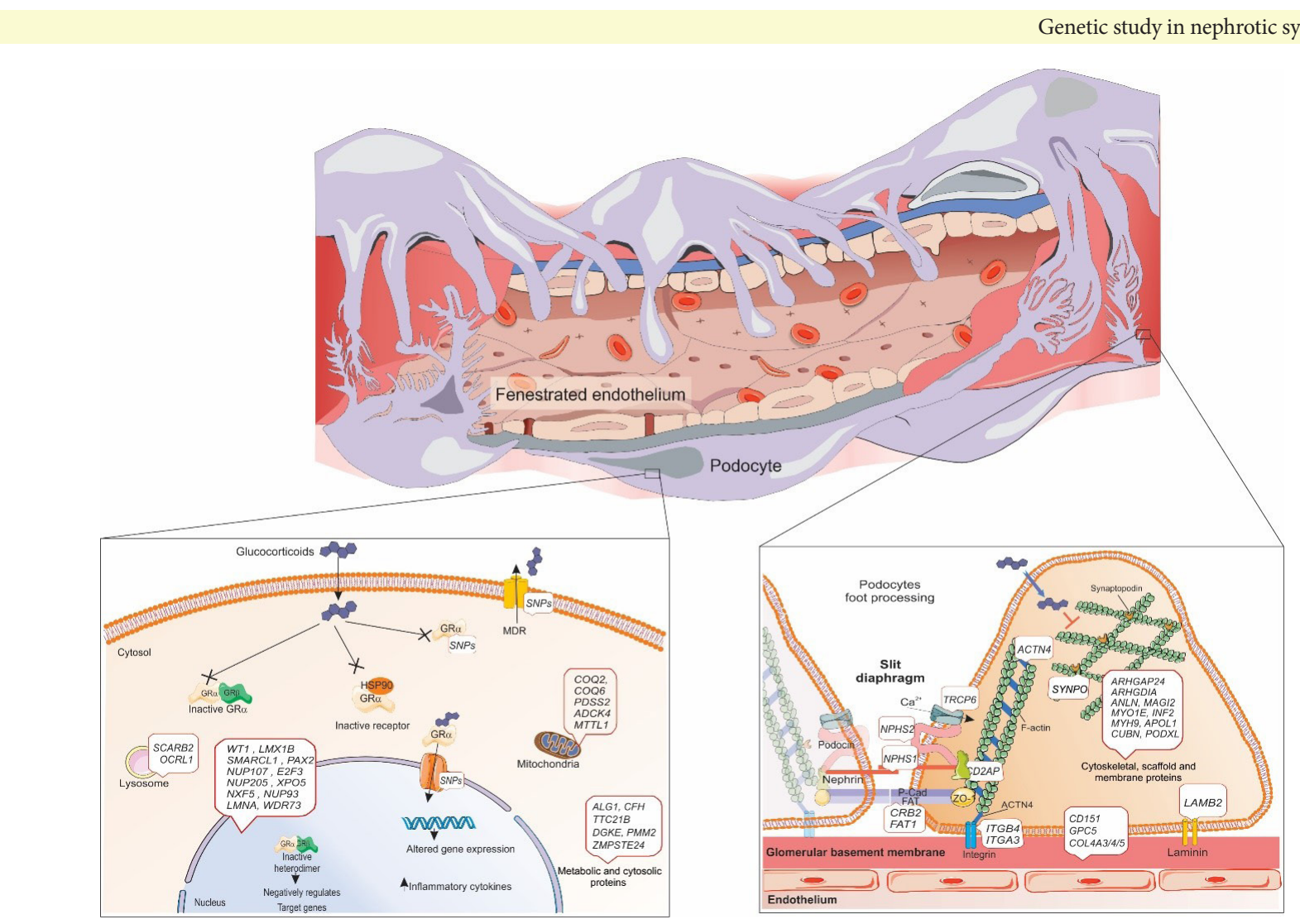

Figure 1. Podocyte genetic mutations associated with steroid-resistant nephrotic syndrome (SRNS). Glomerular filtration barrier (GFB) consists of 3 layers, podocytes, glomerular basement membrane (GBM), and fenestrated endothelium. Podocytes are linked by intercellular slit diaphragm (SD) and made a condensed layer on the urinary side of the GFB. Gene mutations are grouped based on their function and location within the GFB and the full names of their-encoded proteins are as follows:

COQ: coenzyme Q, PDSS2: prenyl-diphosphate synthase subunit 2, ADCK4: AarF domain-containing kinase 4, MTTL1: mitochondrial lyencoded tRNA leucine1, SCARB2: scavenger receptor class B, PMM2: phosphomannomutase2, ALG1: chitobiosyldiphosphodolichol $\beta$-mannosyltransferase, WT1: Wilm's tumor protein 1, SMARCAL1: SMARCA-like protein, NUP: nuclear pore complex protein, XPO5: exportin 5, LMX1B: LIM homeo box transcription factor1b, NXF5: nuclear RNA export factor 5, PAX2: paired box protein, E2F3: E2F3 transcription factor, LMNA: lamina A and C, ZMPSTE24: zinc metallopeptidase STE 24, NPHS1: nephrin, NPHS2: podocin, CD2AP: CD2-associatedprotein, PLCE1: phospholipase C epsilon 1, TRPC6: transient receptor potential channel 6, FAT1: FAT atypical cadherin 1, PTPRO: protein tyrosine phosphatase receptor type O, CRB2: Crumbs family member 2, ACTN4: a-actinin-4, SYNPO: synaptopodin, PODXL: podocalyxin, INF2: inverted formin 2, MYO1E: myosin 1E, MAGI2: membrane associated guanylate kinase, PTPRO: protein-tyrosine phosphatase-R O, ARHGDIA: Rho-GDP-dissociation inhibitor alpha, ARHGAP24: Rho-GTPase-activating protein24, ANLN: anillin actinbinding protein, CUBN: cubilin, APOL1: apolipoprotein L1, EMP2: epithelial membrane protein 2, IFT139, TTC21B: tetratricopeptide repeat protein21B.

mutations. The type and frequency of these identified mutations vary among different ethnics (46). In a worldwide cohort study, investigations indicated one or more loss of function mutations in NPHS2 like p.R138Q (39.1\%) in patients with congenital NS (47). p.R138Q is mainly associated with earlier-NS onset compared to other podocin mutations and leads to severe phenotype. p.R138Q mutation produces a truncated-podocin that is entrapped in the endoplasmic reticulum and disturbs nephrin transport to its target site in the cell membrane (48) and leads to early-onset SRNS. In children before six years of age, homozygous p.R138Q mutations lead to NS. In a study, children from $93.3 \%$ of families with NS exhibited the disease in the first year of life. These patients carried p.R138Q mutation or more than one missense NPHS2 mutation in their genome (49). p.R138X is the other NPHS2 mutation in which truncated podocin cannot interact with membrane lipid rafts and nephrin signaling is prohibited (48). The phenotype of this mutation is observed as early and late-onset SRNS, FSGS, and also in diffuse mesangial proliferation. p.A284V and p.R229Q have been detected as the most common variants in Chilean SRNS children (50). Combination of p.R229Q and p.A284V leads to resistance to steroids and other types of immunosuppression. In these patients, FSGS progressed to ESRD in an average time of 8 years (51). The binding affinity of p.R229Q-mutated-podocin to nephrin is reduced that explains the mild phenotype of the mutation and late-onset of disease (52). Adult-onset SRNS is associated with various NPHS2 mutations, mostly with R229Q (51,53). A compound heterozygous variant of NPHS2 R229Q and a pathogenic variant in exon 7 or 8 predispose carriers to develop NS in adulthood and cause resistance to corticoids or immunosuppressors. However, if the pathogenic variant is on exons 1 to 6 , the risk decreases (54). Most identified NPHS2 mutations are 
associated with SRNS. This necessitates investigation to find NPHS2 mutations in patients with SRNS to discover if patients are sensitive to steroids (39).

\section{WT1 protein}

Wilm's tumor protein (WT1) gene mutations are reported in children (5\%-9\%) with early-onset steroid SRNS (16). A higher incidence is reported in infantile or congenital NS and in children with diffuse mesangial sclerosis (DMS) $(14,55)$. WT1, harbouring 10 exons, encodes for a transcriptional factor protein that is participated in a wide variety of physiological functions including induction of the mesenchymal-epithelial transition process and various developmental and transcriptional pathways of nephrogenesis (56). In mature developed kidneys, WT1 is expressed in epithelial cells of Bowman's capsule and podocytes (57). WT1 isoforms have different roles in the development and physiology of the kidney $(58,59)$. WT1 gene mutations affect the production of SD proteins such as nephrin and podocalyxin (60). Denys-Drash syndrome (DDS), NS type 4 (NPHS4), and Frasier syndrome (FS) are three main nephropathies associated with WT1 mutation and are associated with SRNS. DDS patients are suffering from early-onset SRNS, male pseudo-hermaphroditism, and increased probability of developing Wilm's tumors. WT1 coding gene (exons 7-10) encodes four zinc fingers that specifically recognize DNA and RNA sequences and most dominant missense mutations in WT1 occur in exons 8 and 9 (zinc fingers 2 and 3) (57). The most frequent WT1 mutation, p.R394W (exon 9), leads to upregulation of Pax2 transcription factor that is normally suppressed by WT1 (61). Pax-2 is involved in nephrogenesis and podocyte differentiation (62). There is a positive correlation between renal tubular damage and Pax-2 concentration. Frasier syndrome mostly occurs due to mutations in the donor splice site at intron 9 (IVS $9+4 \mathrm{C}>\mathrm{T}$ ). Alternative splicing in exon 9 inserts KTS amino acids between the WT1 zinc fingers (third and fourth ones). Presence or absence of KTS determines the location of protein isoforms. WT1 isoforms without KTS locate in the nucleus and in contrast to WT1 with KTS, actively participate in transcription. The mutation identified as IVS $9+4 \mathrm{C}>\mathrm{T}$ in the intron 9 splice-site, decreases the production of WT1 with KTS and results in FS phenotype (63). FS is described by the presence of complications such as FSGS and progressive glomerulopathy, and gonadoblastoma. This mutation is also found in FSGS patients and normal females (64). Kidney clinical symptoms are detectable at early ages (2-6 years old) and are identified by progressive proteinuria, steroid resistance, FSGS, and finally progression to ESRD. Children with NPHS4 are recognized with isolated DMS, SRNS, and rapid progression to ESRD. In contrast to the concept that NS patients with WT1 mutations are not sensitive to steroid therapy, there are reports, indicating successful treatment with steroids. Children with FSGS,
WT1 mutations, or nephrotic proteinuria showed sensitivity to CsA therapy (57). This observation suggests the existence of an unknown subset of WT1 mutations capable to reduce proteinuria upon CsA therapy.

\section{Phospholipase C Epsilon-1}

Phospholipase C Epsilon-1 (PLCE1) coding gene is highly associated with SRNS (65). PLCE1 hydrolysis phospholipids in membrane to create inositol 1,4,5trisphosphate (IP3) and diacylglycerol (DAG), the second messenger molecules initiating cell growth intracellular pathways. This enzyme participates in signaling pathways and induces structural development in podocytes. In NS type 3 (NPHS3) patients, homozygous or compound heterozygous PLCE1mutations have been identified. These patients develop severe early-onset NS associated with SRNS, proteinuria, and rapid ESRD development (66). Moreover, the association of PLCE1 mutations with congenital NS, DMS, and in the non-negligible proportion of patients with FSGS with no NPHS2 mutation is reported (66-68). PLCE1 mutations have been detected in hereditary and sporadic forms of FSGS (65). There are reports indicating that patients with PLCE1 truncating mutations, p.R493X and p.Q1854X successfully responded to therapy (66). The authors suggested that children partially responding to therapy, probably another family member of PLC protein may take over and via an indefinite mechanism compensate for the loss of PLCE1 function. Consequently, cases with PLCE1 mutations may respond well to immunosuppressive treatment in the absence of other gene mutations (69).

\section{CD2-associated protein}

CD2-associated protein (CD2AP) is associated with the C-terminal of cell adhesion molecule (CD2) on podocytes, natural killer cells, and $\mathrm{T}$ lymphocytes. CD2AP interacts with cytoskeletal content of podocytes, fyn, and synaptopodin, and maintain the architecture of the cells (70). Moreover, its interaction with nephrin and podocin has been indicated which emphasizes on the role of CD2AP in protein signaling (71). CD2AP heterozygous (p.T374A) and homozygous (p.R612X) gene mutations are found in steroid-resistant FSGS patients (72-74). Recessive CD2AP mutations are not prevalent in SRNS children (75). p.R612X homozygous mutation resulting in a premature stop codon gives rise to production of a truncated protein with lower ability to bind F-actin diagnosed in a FSGS patient. Absence of CD2AP in mice caused massive proteinuria and death shortly after birth. Heterozygote mutation of CD2AP in mice resulted in the occurrence of glomerular injury after nine months of birth (76).

\section{Inverted formin 2}

Inverted formin 2 (INF2), plays a role in the regulation of 
actin polymerization of the cytoskeleton in different organs such as heart, placenta, kidney, and liver. Heterozygous INF2 mutations are found in hereditary kidney disease, FSGS5 (OMIM \#613237) and a subgroup of cases with Charcot-Marie-Tooth (CMT) disease-associated FSGS (77). INF2, a member of formin family, consists of a diaphanous inhibitory domain (DID), a C-terminal diaphanous autoregulatory domain (DAD), and the formin homology domains (FH1 and FH2). FH2 interaction with actin is necessary to regulate the polymerization of the cytoskeleton and DID-DAD interaction blocks this function (78). INF2 mutations mostly are located on exon 2 (c.317G >C (p.Arg106Pro), c.451T>C (p.Cys151Arg)) and 4 (c.530G >A (p.Arg177His), c.550G>A (p.Glu184Lys)) of DID domain and are related to familial and rarely sporadic (p.R218Q) autosomal-dominant FSGS patients $(79,80)$. Other mutations related to other exons (e.g. p.L245P, exon 6) are also reported. Then, to find disease-related mutations, the entire INF2 gene should be considered (81). INF2 mutations are more frequent in late-onset SRNS and cause proteinuria in early adolescence or adulthood and progress to ESRD. The reduced expression level of INF2 indicates podocyte damage and is associated with the severity of SRNS (82).

\section{TRPC6}

Transient receptor potential canonical 6 subfamily C, member 6 (TRPC6), is a $\mathrm{Ca}^{2+}$ ion channel and regulates intracellular calcium influx into the podocytes. Mutations in TRPC6 lead to late-onset FSGS2 (OMIM \#603965) (83). Moreover, TRPC6 mutations are involved in childhoodonset SRNS and FSGS in familial and sporadic SRNS cases (84-86). Mir et al investigated TRPC6 gene variants in 25 children with SRNS and found 5 patients with hereditary and 11 patients with sporadic SRNS carrying (c.171+ 86 $\mathrm{G}>\mathrm{C}$ and $\mathrm{c} .171+16 \mathrm{~A}>\mathrm{G}$ ) intronic nucleotide substitution, A404V missense, and N561N synonymous variants. Resistance to CsA and CP treatment was observed in these patients (84). Riehle et al identified 19 TRPC6 mutations related to FSGS consisted of both gain- and loss-offunction mutations (83). Gain-of-function mutations (p.E897K, p.R895C, p.P112Q) augment ion flux into podocytes and induce $\mathrm{Ca}^{2+}$ ion signaling. These mutations are mostly presented in patients with adolescence or early adulthood- onset of disease (86). On the contrary, loss of function mutations (N125S, L395A, G757D, L780P) is associated with early-onset of SRNS/FSGS in patients (83). It should be considered that there are differences in the phenotype of these mutants in different populations. For instance, promoter mutation $(-254 \mathrm{C}>\mathrm{G})$ identified in SRNS patients is not related to therapy susceptibility in Indian population (87), however, a probable association is indicated in Chinese children (88). Resistance to therapy is indicated in SRNS patients, presenting various TRPC6 mutations. Santin et al identified p.L780P variant, a novel missense substitution, in a-7-year of age mesangial proliferative FSGS patient. They responded partially to CsA and MMF and no susceptibility to prednisolone was observed. No clinical symptoms was identified in her family members with the same substitution (89). Therefore, TRPC6 gene screening in SRNS with FSGS patients could be considered after the exclusion of other possible associated genes.

\section{Actinin alpha-4}

Actinin alpha 4 (ACTN4), an actin-filament crosslinking protein, organizes cytoskeletal architecture. Dominant ACTN4 mutations occur within the actin-binding domain of the protein and affect the binding ability of $\alpha$-actinin to adhesion molecules, perturb filament assembly in podocytes, and interfere with their function $(90,91)$. Furthermore, ACTN4 interacts with the glucocorticoid receptor (GR) and activates target gene transcription (92). Multiple missense mutations in ACTN4 coding gene and loss of protein expression have been associated with adultonset autosomal dominant form of familial FSGS (OMIM \#603278)(75).

ACTN4 mutations (K255E, T259I, and S262P) found in three unrelated families and more abundantly happen in the binding domain and elevate its binding affinity to filamentous actin in comparison to wild-type protein (9395). Identified mutations caused low-grade proteinuria in early adulthood and can progress to ESRD. W59R and I149del are two other identified mutations in ACTN4 that are found in FSGS patients (91). These five mutations occur in low proportion, around $4 \%$ of familial FSGS (96). Two mutations found in the same location (S262F and S262P) in FSGS patients with early childhood-onset (97). Patients with S262F mutation were two siblings and their father was also carrying the germline mosaicism for the mutation. They demonstrated variable clinical and pathological features. The siblings were found to have a substitution in NPHS1, Thr5Met. The function of this substitution is not clear (97). It is recommended to screen the ACTN4 gene in kids with infantile- or childhoodonset FSGS in cases when screening for mutations in other candidate genes is negative.

\section{Mitochondrial and other rare genes}

Abnormal aggregated mitochondria in basement membrane, podocytes, and epithelial cells of Bowman's capsule has been detected as an underlying cause of FSGS. It seems mutations in mitochondrial DNA are also involved in the pathogenesis of FSGS (98). FSGS is predominantly associated with a subclass of mitochondrial disorder, lactic acidosis, mitochondrial encephalomyopathy, and stroke-like episodes (MELAS). However, mitochondrial DNA (mtDNA) 3243A $>$ G mutation is also identified in patients with FSGS associated with chronic progressive external ophthalmoplegia (CPEO), hearing loss, (cardio) 
myopathy, and diabetes mellitus (99). A3243G transition is reported to be associated with SRNS in an adult patient (100). In vitro investigations indicated A3243G mutation leads to deficiency in the mitochondrial respiratory chain and impaired protein synthesis process. Other tRNA mutations, m.5538G $>$ A, m.A5728G, m.A5843G $\left(\mathrm{tRNA}^{\mathrm{Tyr}}\right.$ ) are found in FSGS-associated mitochondrial diseases (101-103). These mutations are related to a variety of symptoms. A4269G mutation (tRNA ${ }^{\text {Ile }}$ gene) in a patient showed association with mitochondrial encephalomyopathy and hearing loss, epilepsy, FSGS, and myopathy (104). From these studies, it is recommended that, in patients with heterogeneous complications in muscle and nervous systems, diabetes, loss of hearing, and renal diseases, mitochondrial DNA mutations should be considered.

Coenzyme Q (CoQ10) is a lipophilic antioxidant and dehydrogenase cofactor located in the mitochondrial respiratory chain and involves in the biosynthesis of pyrimidines and production of ATP (105). Mutations in CoQ10 represent a wide range of symptoms from deafness, retinitis pigmentosa, ataxia, encephalomyopathy to multi-organ involvement and kidney diseases (105). These manifestations are both in adult- and adolescenceonset with the familial and sporadic origin. Association between SRNS and mutations in coding genes of COQ2 (106), COQ6 (107,108), and PDSS2 (105), and aarF domain containing kinase 4 (ADCK4) (26)(enzymes in CoQ10 biosynthetic pathway) have been demonstrated. Mutations in ADCK4, located in foot processes and mitochondria of podocytes, are related to glomerular disease phenotype and CoQ10 deficiency (26).

\section{Other genes}

Among potential factors engaged in the development of steroid resistance, polymorphisms in cytokine genes should be mentioned, especially in IL-4, IL6, TNF-a (tumor necrosis factor-alpha) genes (109). Jafar et al demonstrated correlations between NS and polymorphisms in IL-6 (G174C), TNF-a (G308A), and IL-4 (C590T) as well as their marked role in diagnosis of SRNS. In addition, the IL-4 polymorphism correlated with predisposition to the minimal change NS (109).

\section{Concluding remarks}

FSGS is a histologic pattern of glomerular injury that may happen in several circumstances. Most of the time, it is secondary to conditions with glomerular hyperfiltration. FSGS could be mediated by an unknown circulating factor(s) that affect the podocytes and glomerular filtration barriers. A small but significant subset of FSGS cases causes by mutations in single genes which affect podocyte development, structure, and function. Clinically, monogenic FSGS most often presents as SRNS (110). Recently, more podocyte-centric thinking has been developed by the discovery that different heritable forms of NS are initiated by mutations of proteins involved in podocyte development, structure, and function.

We clearly and desperately need novel therapeutic methods for patients with inherited glomerular disease that up to now have been suffering from lack of any specific and effective treatment. While we are pursuing those efforts, it is imperative to know that genetic testing does not give absolute answers to all existing questions in this area $(90,110)$. The current movement is giving support to establish genetic, epigenetic, and signaling studies toward precision and personalized medicine in the field of nephrology.

Diagnostic genetic testing could be aimed to identify common gene mutations at the first stages of the disease and deliver more personalized treatment (13). Additionally, they have prognostic information and prevent exposure to unnecessary treatment that patient is unlikely to benefit from (4). Since the SRNS hereditary forms comprise a large number of genes, NGS technology can be used for simultaneous evaluation of all genes involved in podocytopathy (6). The PodoNet Registry has provided complete genetic and clinical information on SRNS cases and aims to make essential visions on genotype-phenotype associations, the efficacy of treatment, and long-term outcomes of the patients and kidney comprising recurrence of disease after transplant (1).

\section{Authors' contribution}

SZV and MRA designed the study. HMS, SMH, ZNAF and $\mathrm{MH}$ prepared the first draft. SZV, MRA and MAMS revised the manuscript. All authors read and signed the final paper.

\section{Conflicts of interest}

The authors declared no competing interests.

\section{Ethical considerations}

Ethical issues including plagiarism, double publication, and redundancy have been completely observed by the authors.

\section{Funding/Support}

This research was funded by National Institute for Medical Research Development (NIMAD Grant \# 958376).

\section{References}

1. Trautmann A, Lipska-Zietkiewicz BS, Schaefer F. Exploring the Clinical and Genetic Spectrum of Steroid Resistant Nephrotic Syndrome: The PodoNet Registry. Front Pediatr. 2018;6: 200. doi: 10.3389/fped.2018.00200.

2. Tasic V, Gucev Z, Polenakovic M. Steroid Resistant Nephrotic Syndrome-Genetic Consideration. Pril (Makedon Akad Nauk Umet Odd Med Nauki). 2015;36: 5-12. doi: 10.1515/prilozi-2015-0073.

3. Tullus K, Webb H, Bagga A. Management of steroidresistant nephrotic syndrome in children and adolescents. 
Lancet Child Adolesc Health. 2018;2: 880-890. doi: 10.1016/ S2352-4642(18)30283-9.

4. Lombel RM, Hodson EM, Gipson DS. Treatment of steroidresistant nephrotic syndrome in children: new guidelines from KDIGO. Pediatr Nephrol. 2013;28: 409-14. doi: 10.1007/s00467-012-2304-8.

5. Trautmann A, Bodria M, Ozaltin F, Gheisari A, Melk A, Azocar M, et al. Spectrum of steroid-resistant and congenital nephrotic syndrome in children: the PodoNet registry cohort. Clin J Am Soc Nephrol. 2015;10: 592-600. doi: $\quad 10.2215 / C J N .06260614$.

6. Preston R, Stuart HM, Lennon R. Genetic testing in steroidresistant nephrotic syndrome: why, who, when and how? Pediatr Nephrol. 2019;34: 195-210. doi: 10.1007/s00467017-3838-6.

7. Giglio S, Provenzano A, Mazzinghi B, Becherucci F, Giunti L, Sansavini G, et al. Heterogeneous genetic alterations in sporadic nephrotic syndrome associate with resistance to immunosuppression. J Am Soc Nephrol. 2015;26: 230-6. doi: 10.1681/ASN.2013111155.

8. Wiggins RC. The spectrum of podocytopathies: a unifying view of glomerular diseases. Kidney Int. 2007;71: 1205-14.

9. Saleem MA. New developments in steroid-resistant nephrotic syndrome. Pediatr Nephrol. 2013;28: 699-709. doi: $\quad 10.1007 / \mathrm{s} 00467-012-2239-0$.

10. Rheault MN, Gbadegesin RA. The Genetics of Nephrotic Syndrome. J Pediatr Genet. 2016;5: 15-24. doi: 10.1055/s0035-1557109.

11. Hall G, Gbadegesin RA. Translating genetic findings in hereditary nephrotic syndrome: the missing loops. Am J Physiol Renal Physiol. 2015;309: F24-8.

12. Garg P. A Review of Podocyte Biology. Am J Nephrol. 2018;47: 3-13.

13. Bierzynska A, Soderquest K, Koziell A. Genes and podocytes - new insights into mechanisms of podocytopathy. Front Endocrinol (Lausanne). 2014;5: 226.

14. Sadowski CE, Lovric S, Ashraf S, Pabst WL, Gee HY, Kohl S, et al. A single-gene cause in $29.5 \%$ of cases of steroidresistant nephrotic syndrome. J Am Soc Nephrol. 2015;26: 1279-89.

15. Hinkes BG, Mucha B, Vlangos CN, Gbadegesin R, Liu J, Hasselbacher K, et al. Nephrotic syndrome in the first year of life: two thirds of cases are caused by mutations in 4 genes (NPHS1, NPHS2, WT1, and LAMB2). Pediatrics. 2007;119: e907-19.

16. Wang F, Zhang Y, Mao J, Yu Z, Yi Z, Yu L, et al. Spectrum of mutations in Chinese children with steroid-resistant nephrotic syndrome. Pediatr Nephrol. 2017;32: 1181-1192.

17. Hasselbacher K, Wiggins RC, Matejas V, Hinkes BG, Mucha $\mathrm{B}$, Hoskins $\mathrm{BE}$, et al. Recessive missense mutations in LAMB2 expand the clinical spectrum of LAMB2-associated disorders. Kidney Int. 2006;70: 1008-12.

18. Zhao F, Zhu JY, Richman A, Fu Y, Huang W, Chen N, et al. Mutations in NUP160 Are Implicated in Steroid-Resistant Nephrotic Syndrome. J Am Soc Nephrol. 2019;30: 840-853. doi: 10.1681/ASN.2018080786.

19. Rossanti R, Shono A, Miura K, Hattori M, Yamamura T, Nakanishi K, et al. Molecular assay for an intronic variant in NUP93 that causes steroid resistant nephrotic syndrome. J Hum Genet. 2019. doi: 10.1038/s10038-019-0606-4.
20. Zivicnjak M, Franke D, Zenker M, Hoyer J, Lucke T, Pape L, et al. SMARCAL1 mutations: a cause of prepubertal idiopathic steroid-resistant nephrotic syndrome. Pediatr Res. 2009;65: 564-8. doi: 10.1203/PDR.0b013e3181998a74.

21. Hyun HS, Kim SH, Park E, Cho MH, Kang HG, Lee HS, et al. A familial case of Galloway-Mowat syndrome due to a novel TP53RK mutation: a case report. BMC Med Genet. 2018;19: 131.

22. Sethi S, Fervenza FC, Zhang Y, Smith RJ. Secondary focal and segmental glomerulosclerosis associated with single-nucleotide polymorphisms in the genes encoding complement factor H and C3. Am J Kidney Dis. 2012;60: 316-21. doi: 10.1053/j.ajkd.2012.04.011.

23. Quinzii C, Naini A, Salviati L, Trevisson E, Navas P, Dimauro S, et al. A mutation in para-hydroxybenzoatepolyprenyl transferase (COQ2) causes primary coenzyme Q10 deficiency. Am J Hum Genet. 2006;78: 345-9.

24. Diomedi-Camassei F, Di Giandomenico S, Santorelli FM, Caridi G, Piemonte F, Montini G, et al. COQ2 nephropathy: a newly described inherited mitochondriopathy with primary renal involvement. J Am Soc Nephrol. 2007;18: 2773-80.

25. Lopez LC, Schuelke M, Quinzii CM, Kanki T, Rodenburg RJ, Naini A, et al. Leigh syndrome with nephropathy and CoQ10 deficiency due to decaprenyl diphosphate synthase subunit 2 (PDSS2) mutations. Am J Hum Genet. 2006;79: 1125-9.

26. Ashraf S, Gee HY, Woerner S, Xie LX, Vega-Warner $\mathrm{V}$, Lovric S, et al. ADCK4 mutations promote steroidresistant nephrotic syndrome through CoQ10 biosynthesis disruption. J Clin Invest. 2013;123: 5179-89.

27. Ozaltin F, Ibsirlioglu T, Taskiran EZ, Baydar DE, Kaymaz F, Buyukcelik M, et al. Disruption of PTPRO causes childhood-onset nephrotic syndrome. Am J Hum Genet. 2011;89: 139-47.

28. Hermle T, Schneider R, Schapiro D, Braun DA, van der Ven AT, Warejko JK, et al. GAPVD1 and ANKFY1 Mutations Implicate RAB5 Regulation in Nephrotic Syndrome. J Am Soc Nephrol. 2018;29: 2123-2138. doi: 10.1681/ ASN.2017121312.

29. Gee HY, Zhang F, Ashraf S, Kohl S, Sadowski CE, VegaWarner V, et al. KANK deficiency leads to podocyte dysfunction and nephrotic syndrome. J Clin Invest. 2015;125: 2375-84.

30. Gee HY, Saisawat P, Ashraf S, Hurd TW, Vega-Warner $\mathrm{V}$, Fang $\mathrm{H}$, et al. ARHGDIA mutations cause nephrotic syndrome via defective RHO GTPase signaling. J Clin Invest. 2013;123: 3243-53. doi: 10.1172/JCI69134.

31. Akilesh S, Suleiman H, Yu H, Stander MC, Lavin P, Gbadegesin R, et al. Arhgap24 inactivates Rac1 in mouse podocytes, and a mutant form is associated with familial focal segmental glomerulosclerosis. J Clin Invest. 2011;121: 4127-37. doi: 10.1172/JCI46458.

32. Bierzynska A, Soderquest K, Dean P, Colby E, Rollason $\mathrm{R}$, Jones C, et al. MAGI2 Mutations Cause Congenital Nephrotic Syndrome. J Am Soc Nephrol. 2017;28: 16141621. doi: 10.1681/ASN.2016040387.

33. Ebarasi L, Ashraf S, Bierzynska A, Gee HY, McCarthy HJ, Lovric S, et al. Defects of CRB2 cause steroid-resistant nephrotic syndrome. Am J Hum Genet. 2015;96: 153-61. 
doi: $\quad$ 10.1016/j.ajhg.2014.11.014.

34. Sanna-Cherchi S, Burgess KE, Nees SN, Caridi G, Weng PL, Dagnino M, et al. Exome sequencing identified MYO1E and NEIL1 as candidate genes for human autosomal recessive steroid-resistant nephrotic syndrome. Kidney Int. 2011;80: 389-96. doi: 10.1038/ki.2011.148.

35. Braun DA, Sadowski CE, Kohl S, Lovric S, Astrinidis SA, Pabst WL, et al. Mutations in nuclear pore genes NUP93, NUP205 and XPO5 cause steroid-resistant nephrotic syndrome. Nat Genet. 2016;48: 457-65.

36. Li J, Wang L, Wan L, Lin T, Zhao W, Cui H, et al. Mutational spectrum and novel candidate genes in Chinese children with sporadic steroid-resistant nephrotic syndrome. Pediatr Res. 2019;85: 816-821.

37. Miyake N, Tsukaguchi H, Koshimizu E, Shono A, Matsunaga S, Shiina M, et al. Biallelic Mutations in Nuclear Pore Complex Subunit NUP107 Cause Early-ChildhoodOnset Steroid-Resistant Nephrotic Syndrome. Am J Hum Genet. 2015;97: 555-66.

38. Martin CE, Jones N. Nephrin signaling in the podocyte: an updated view of signal regulation at the slit diaphragm and beyond. Front Endocrinol (Lausanne). 2018;9: 302.

39. Joshi S, Andersen R, Jespersen B, Rittig S. Genetics of steroid-resistant nephrotic syndrome: a review of mutation spectrum and suggested approach for genetic testing. Acta Paediatr. 2013;102: 844-56.

40. Patrakka J, Ruotsalainen V, Reponen P, Qvist E, Laine J, Holmberg C, et al. Recurrence of nephrotic syndrome in kidney grafts of patients with congenital nephrotic syndrome of the Finnish type: role of nephrin. Transplantation. 2002;73: 394-403.

41. Koziell A, Grech V, Hussain S, Lee G, Lenkkeri U, Tryggvason K, et al. Genotype/phenotype correlations of NPHS1 and NPHS2 mutations in nephrotic syndrome advocate a functional inter-relationship in glomerular filtration. Hum Mol Genet. 2002;11: 379-88.

42. Philippe A, Nevo F, Esquivel EL, Reklaityte D, Gribouval O, Tete MJ, et al. Nephrin mutations can cause childhoodonset steroid-resistant nephrotic syndrome. J Am Soc Nephrol. 2008;19: 1871-8.

43. Santin S, Garcia-Maset R, Ruiz P, Gimenez I, Zamora I, Pena A, et al. Nephrin mutations cause childhood- and adult-onset focal segmental glomerulosclerosis. Kidney Int. 2009;76: 1268-76. doi: 10.1038/ki.2009.381.

44. Thomas MM, Abdel-Hamid MS, Mahfouz NN, Ghobrial EE. Genetic mutation in Egyptian children with steroidresistant nephrotic syndrome. J Formos Med Assoc. 2018;117: 48-53.

45. Guaragna MS, Lutaif A, Maciel-Guerra AT, Belangero VMS, Guerra-Junior G, De Mello MP. NPHS2 Mutations: A Closer Look to Latin American Countries. Biomed Res Int. 2017;2017: 7518789 .

46. Bouchireb K, Boyer O, Gribouval O, Nevo F, Huynh-Cong E, Moriniere V, et al. NPHS2 mutations in steroid-resistant nephrotic syndrome: a mutation update and the associated phenotypic spectrum. Hum Mutat. 2014;35: 178-86.

47. Weber S, Gribouval O, Esquivel EL, Moriniere V, Tete MJ, Legendre C, et al. NPHS2 mutation analysis shows genetic heterogeneity of steroid-resistant nephrotic syndrome and low post-transplant recurrence. Kidney Int. 2004;66: 571-9.
DOI:10.1111/j.1523-1755.2004.00776.x.

48. Huber TB, Simons M, Hartleben B, Sernetz L, Schmidts M, Gundlach E, et al. Molecular basis of the functional podocin-nephrin complex: mutations in the NPHS2 gene disrupt nephrin targeting to lipid raft microdomains. Hum Mol Genet. 2003;12: 3397-405. DOI:10.1093/hmg/ddg360.

49. Hinkes BG, Mucha B, Vlangos CN, Gbadegesin R, Liu J, Hasselbacher K, et al. Nephrotic syndrome in the first year of life: two thirds of cases are caused by mutations in 4 genes (NPHS1, NPHS2, WT1, and LAMB2). Pediatrics. 2007;119: e907-e919.

50. Azocar M, Vega A, Farfan M, Cano F. [NPHS2 Mutation analysis study in children with steroid-resistant nephrotic syndrome]. Rev Chil Pediatr. 2016;87: 31-6. doi: 10.1016/j. rchipe.2015.06.025.

51. Santin S, Tazon-Vega B, Silva I, Cobo MA, Gimenez I, Ruiz $\mathrm{P}$, et al. Clinical value of NPHS2 analysis in early- and adultonset steroid-resistant nephrotic syndrome. Clin J Am Soc Nephrol. 2011;6: 344-54.

52. Tsukaguchi H, Sudhakar A, Le TC, Nguyen T, Yao J, Schwimmer JA, et al. NPHS2 mutations in late-onset focal segmental glomerulosclerosis: R229Q is a common diseaseassociated allele. J Clin Invest. 2002;110: 1659-1666.

53. Gribouval O, Boyer O, Hummel A, Dantal J, Martinez F, Sberro-Soussan R, et al. Identification of genetic causes for sporadic steroid-resistant nephrotic syndrome in adults. Kidney Int. 2018;94: 1013-1022. doi: 10.1016/j. kint.2018.07.024.

54. Rood IM, Deegens JKJ, Lugtenberg D, Bongers E, Wetzels JFM. Nephrotic Syndrome With Mutations in NPHS2: The Role of R229Q and Implications for Genetic Counseling. Am J Kidney Dis. 2018; 73:400-403. doi: 10.1053/j. ajkd.2018.06.034.

55. Lipska BS, Ranchin B, Iatropoulos P, Gellermann J, Melk A, Ozaltin F, et al. Genotype-phenotype associations in WT1 glomerulopathy. Kidney Int. 2014;85: 1169-78. doi: 10.1038/ki.2013.519.

56. Hartwig S, Ho J, Pandey P, Macisaac K, Taglienti M, Xiang $\mathrm{M}$, et al. Genomic characterization of Wilms' tumor suppressor 1 targets in nephron progenitor cells during kidney development. Development. 2010;137: 1189-203. doi: $10.1242 /$ dev.045732.

57. Stefanidis CJ, Querfeld U. The podocyte as a target: cyclosporin $\mathrm{A}$ in the management of the nephrotic syndrome caused by WT1 mutations. Eur J Pediatr. 2011;170: 1377-83.

58. Ito K, Oji Y, Tatsumi N, Shimizu S, Kanai Y, Nakazawa T, et al. Antiapoptotic function of 17AA(+)WT1 (Wilms' tumor gene) isoforms on the intrinsic apoptosis pathway. Oncogene. 2006;25: 4217-29.

59. Lefebvre J, Clarkson M, Massa F, Bradford ST, Charlet A, Buske F, et al. Alternatively spliced isoforms of WT1 control podocyte-specific gene expression. Kidney Int. 2015;88: 321-31. doi: 10.1038/ki.2015.140.

60. Hall G, Gbadegesin RA, Lavin P, Wu G, Liu Y, Oh EC, et al. A novel missense mutation of Wilms' Tumor 1 causes autosomal dominant FSGS. J Am Soc Nephrol. 2015;26: 831-43.

61. Morrison AA, Viney RL, Saleem MA, Ladomery MR. New insights into the function of the Wilms tumor suppressor 
gene WT1 in podocytes. Am J Physiol Renal Physiol. 2008;295: F12-7. doi: 10.1152/ajprenal.00597.2007.

62. Reidy KJ, Rosenblum ND. Cell and molecular biology of kidney development. Semin Nephrol. 2009;29: 321-37. doi: 10.1016/j.semnephrol.2009.03.009.

63. Yang C, Romaniuk PJ. The ratio of $+/$-KTS splice variants of the Wilms' tumour suppressor protein WT1 mRNA is determined by an intronic enhancer. Biochem Cell Biol. 2008;86: 312-21. doi: 10.1139/o08-075.

64. Hersmus R, van der Zwan YG, Stoop H, Bernard P, Sreenivasan R, Oosterhuis JW, et al. A 46,XY female DSD patient with bilateral gonadoblastoma, a novel SRY missense mutation combined with a WT1 KTS splice-site mutation. PLoS One. 2012;7: e40858.

65. Boyer O, Benoit G, Gribouval O, Nevo F, Pawtowski A, Bilge I, et al. Mutational analysis of the PLCE1 gene in steroid resistant nephrotic syndrome. J Med Genet. 2010;47: 44552. doi: 10.1136/jmg.2009.076166.

66. Hinkes B, Wiggins RC, Gbadegesin R, Vlangos CN, Seelow $D$, Nürnberg G, et al. Positional cloning uncovers mutations in PLCE1 responsible for a nephrotic syndrome variant that may be reversible. Nat Genet. 2006;38: 1397.

67. Machuca E, Benoit G, Nevo F, Tête M-J, Gribouval O, Pawtowski A, et al. Genotype-phenotype correlations in non-Finnish congenital nephrotic syndrome. J Am Soc Nephrol. 2010;21:1209-17. doi: 10.1681/ASN.2009121309.

68. Gbadegesin R, Hinkes BG, Hoskins BE, Vlangos CN, Heeringa SF, Liu J, et al. Mutations in PLCE1 are a major cause of isolated diffuse mesangial sclerosis (IDMS). Nephrol Dial Transplant. 2008;23:1291-1297. DOI:10.1093/ ndt/gfm759.

69. Joshi S, Andersen R, Jespersen B, Rittig SJAp. Genetics of steroid-resistant nephrotic syndrome: a review of mutation spectrum and suggested approach for genetic testing. Acta Paediatr. 2013;102:844-856.

70. Nourbakhsh N, Mak RH. Steroid-resistant nephrotic syndrome: past and current perspectives. Pediatric Health Med Ther. 2017;8: 29-37.

71. Ha TS. Roles of adaptor proteins in podocyte biology. World J Nephrol. 2013;2: 1-10.

72. Tsvetkov D, Hohmann M, Anistan YM, Mannaa M, Harteneck C, Rudolph B, et al. A CD2AP Mutation Associated with Focal Segmental Glomerulosclerosis in Young Adulthood. Clin Med Insights Case Rep. 2016;9: 159.

73. Lowik MM, Groenen PJ, Pronk I, Lilien MR, Goldschmeding $\mathrm{R}$, Dijkman HB, et al. Focal segmental glomerulosclerosis in a patient homozygous for a CD2AP mutation. Kidney Int. 2007;72: 1198-203.

74. Gigante M, Pontrelli P, Montemurno E, Roca L, Aucella F, Penza R, et al. CD2AP mutations are associated with sporadic nephrotic syndrome and focal segmental glomerulosclerosis (FSGS). Nephrol Dial Transplant. 2009;24: $\quad$ 1858-64.

75. Benoit G, Machuca E, Nevo F, Gribouval O, Lepage D, Antignac C. Analysis of recessive CD2AP and ACTN4 mutations in steroid-resistant nephrotic syndrome. Pediatr Nephrol. 2010;25: 445-51.

76. Kim JM, Wu H, Green G, Winkler CA, Kopp JB, Miner JH, et al. CD2-associated protein haploinsufficiency is linked to glomerular disease susceptibility. Science. 2003;300: 1298300.

77. Boyer O, Nevo F, Plaisier E, Funalot B, Gribouval O, Benoit G, et al. INF2 mutations in Charcot-Marie-Tooth disease with glomerulopathy. N Engl J Med. 2011;365: 2377-2388. doi: 10.1056/NEJMoa1109122.

78. Chhabra ES, Ramabhadran V, Gerber SA, Higgs HN. INF2 is an endoplasmic reticulum-associated formin protein. J Cell Sci. 2009;122: 1430-40. doi: 10.1242/jcs.040691.

79. Brown EJ, Schlöndorff JS, Becker DJ, Tsukaguchi H, Tonna SJ, Uscinski AL, et al. Mutations in the formin gene INF2 cause focal segmental glomerulosclerosis. Nat Genet. 2010;42:72-76.

80. Boyer O, Benoit G, Gribouval O, Nevo F, Tete MJ, Dantal $\mathrm{J}$, et al. Mutations in INF2 are a major cause of autosomal dominant focal segmental glomerulosclerosis. J Am Soc Nephrol. 2011;22: 239-45.

81. Sanchez-Ares M, Garcia-Vidal M, Antucho EE, Julio P, Eduardo VM, Lens XM, et al. A novel mutation, outside of the candidate region for diagnosis, in the inverted formin 2 gene can cause focal segmental glomerulosclerosis. Kidney Int. 2013;83: 153-9.

82. Tamura H, Nakazato H, Kuraoka S, Yoneda K, Takahashi W, Endo F. Reduced INF2 expression in nephrotic syndrome is possibly related to clinical severity of steroid resistance in children. Nephrology (Carlton). 2016;21: 467-75.

83. Riehle M, Buscher AK, Gohlke BO, Kassmann M, KolatsiJoannou M, Brasen JH, et al. TRPC6 G757D Loss-ofFunction Mutation Associates with FSGS. J Am Soc Nephrol. 2016;27: 2771-83. doi: 10.1681/ASN.2015030318.

84. Mir S, Yavascan O, Berdeli A, Sozeri B. TRPC6 gene variants in Turkish children with steroid-resistant nephrotic syndrome. Nephrol Dial Transplant. 2012;27: 205-9.

85. Heeringa SF, Moller CC, Du J, Yue L, Hinkes B, Chernin G, et al. A novel TRPC6 mutation that causes childhood FSGS. PLoS One. 2009;4: e7771.

86. Gigante M, Caridi G, Montemurno E, Soccio M, d'Apolito $\mathrm{M}$, Cerullo $\mathrm{G}$, et al. TRPC6 mutations in children with steroid-resistant nephrotic syndrome and atypical phenotype. Clin J Am Soc Nephrol. 2011;6: 1626-34.

87. Mahesh Kumar KB, Prabha S, Ramprasad E, Bhaskar LV, Soundararajan P. TRPC6 gene promoter polymorphisms in steroid resistant nephrotic syndrome children. J Nephropharmacol. 2015;4: 52-56.

88. Kuang XY, Huang WY, Xu H, Shi Y, Zhang XL, Niu XL, et al. 254C>G: a TRPC6 promoter variation associated with enhanced transcription and steroid-resistant nephrotic syndrome in Chinese children. Pediatr Res. 2013;74: 511-6.

89. Santin S, Ars E, Rossetti S, Salido E, Silva I, Garcia-Maset $\mathrm{R}$, et al. TRPC6 mutational analysis in a large cohort of patients with focal segmental glomerulosclerosis. Nephrol Dial Transplant. 2009;24: 3089-96.

90. Chong JX, Buckingham KJ, Jhangiani SN, Boehm C, Sobreira N, Smith JD, et al. The Genetic Basis of Mendelian Phenotypes: Discoveries, Challenges, and Opportunities. Am J Hum Genet. 2015;97: 199-215. doi: 10.1016/j. ajhg.2015.06.009.

91. Feng D, DuMontier C, Pollak MR. The role of alphaactinin-4 in human kidney disease. Cell Biosci. 2015;5: 44.

92. Zhao X, Khurana S, Charkraborty S, Tian Y, Sedor JR, 
Bruggman LA, et al. alpha Actinin 4 (ACTN4) Regulates Glucocorticoid Receptor-mediated Transactivation and Transrepression in Podocytes. J Biol Chem. 2017;292: 16371647.

93. Michaud JL, Chaisson KM, Parks RJ, Kennedy CR. FSGSassociated alpha-actinin-4 (K256E) impairs cytoskeletal dynamics in podocytes. Kidney Int. 2006;70: 1054-61.

94. Smoyer WE, Mundel P, Gupta A, Welsh MJ. Podocyte alpha-actinin induction precedes foot process effacement in experimental nephrotic syndrome. Am J Physiol. 1997;273: F150-7.

95. Kaplan JM, Kim SH, North KN, Rennke H, Correia LA, Tong HQ, et al. Mutations in ACTN4, encoding alphaactinin-4, cause familial focal segmental glomerulosclerosis. Nat Genet. 2000;24: 251-6.

96. Weins A, Kenlan P, Herbert S, Le TC, Villegas I, Kaplan BS, et al. Mutational and Biological Analysis of alpha-actinin-4 in focal segmental glomerulosclerosis. J Am Soc Nephrol. 2005; 16: 3694-701.

97. Choi HJ, Lee BH, Cho HY, Moon KC, Ha IS, Nagata M, et al. Familial focal segmental glomerulosclerosis associated with an ACTN4 mutation and paternal germline mosaicism. Am J Kidney Dis. 2008;51: 834-8.

98. Narumi K, Mishima E, Akiyama Y, Matsuhashi T, Nakamichi T, Kisu K, et al. Focal Segmental Glomerulosclerosis Associated with Chronic Progressive External Ophthalmoplegia and Mitochondrial DNA A3243G Mutation. Nephron. 2018;138: 243-248.

99. Emma F, Salviati L. Mitochondrial cytopathies and the kidney. Nephrol Ther. 2017;13 Suppl 1: S23-s28.

100. Lowik MM, Hol FA, Steenbergen EJ, Wetzels JF, van den Heuvel LP. Mitochondrial tRNALeu(UUR) mutation in a patient with steroid-resistant nephrotic syndrome and focal segmental glomerulosclerosis. Nephrol Dial Transplant. 2005;20: 336-41.

101. Lim K, Steele D, Fenves A, Thadhani R, Heher E, Karaa A. Focal segmental glomerulosclerosis associated with mitochondrial disease. Clin Nephrol Case Stud. 2017;5: 20-
25.

102. Meulemans A, Seneca S, Lagae L, Lissens W, De Paepe B, Smet J, et al. A novel mitochondrial transfer RNA(Asn) mutation causing multiorgan failure. Arch Neurol. 2006;63: 1194-8.

103. Scaglia F, Vogel H, Hawkins EP, Vladutiu GD, Liu LL, Wong LJ. Novel homoplasmic mutation in the mitochondrial tRNATyr gene associated with atypical mitochondrial cytopathy presenting with focal segmental glomerulosclerosis. Am J Med Genet A. 2003;123a:172-8.

104. Taniike M, Fukushima H, Yanagihara I, Tsukamoto H, Tanaka J, Fujimura H, et al. Mitochondrial tRNA(Ile) mutation in fatal cardiomyopathy. Biochem Biophys Res Commun. 1992;186:47-53.

105. Doimo M, Desbats MA, Cerqua C, Cassina M, Trevisson E, Salviati L. Genetics of coenzyme q10 deficiency. Mol Syndromol. 2014;5:156-62. doi: 10.1159/000362826.

106. McCarthy HJ, Bierzynska A, Wherlock M, Ognjanovic M, Kerecuk L, Hegde S, et al. Simultaneous sequencing of 24 genes associated with steroid-resistant nephrotic syndrome. Clin J Am Soc Nephrol. 2013;8:637-48.

107. Heeringa SF, Chernin G, Chaki M, Zhou W, Sloan AJ, Ji Z, et al. COQ6 mutations in human patients produce nephrotic syndrome with sensorineural deafness. J Clin Invest. 2011;121:2013-24. doi: 10.1172/JCI45693.

108. Park E, Ahn YH, Kang HG, Yoo KH, Won NH, Lee KB, et al. COQ6 Mutations in Children With Steroid-Resistant Focal Segmental Glomerulosclerosis and Sensorineural Hearing Loss. Am J Kidney Dis. 2017;70:139-144.

109. Jafar T, Agrawal S, Mahdi AA, Sharma RK, Awasthi S, Agarwal GG. Cytokine gene polymorphism in idiopathic nephrotic syndrome children. Indian J Clin Biochem. 2011;26:296-302.

110. Bierzynska A, McCarthy HJ, Soderquest K, Sen ES, Colby E, Ding WY, et al. Genomic and clinical profiling of a national nephrotic syndrome cohort advocates a precision medicine approach to disease management. Kidney Int. 2017;91: 937 947. doi: 10.1016/j.kint.2016.10.013.

Copyright $\odot 2019$ The Author(s); Published by Nickan Research Institute. This is an open-access article distributed under the terms of the Creative Commons Attribution License (http://creativecommons.org/licenses/by/4.0), which permits unrestricted use, distribution, and reproduction in any medium, provided the original work is properly cited. 